\title{
Transnasal Endoscopic Cerebrospinal Fluid Rhinorrhea Repair: Our Experience of 35 Cases
}

\author{
${ }^{1}$ Avani Jain, ${ }^{2}$ Pawan Singhal, ${ }^{3}$ Man Prakash Sharma, ${ }^{4}$ Shashank Nath Singh, ${ }^{5}$ Mohnish Grover
}

\begin{abstract}
Cerebrospinal fluid rhinorrhea results from a breakdown of barriers between the subarachnoid space and aerodigestive tract. Because of the risk of potential intracranial complications, all persistent cerebrospinal fluid (CSF) leaks should be repaired. Over the past few decades, with the advances in endoscopic techniques, the surgical management of CSF rhinorrhea has changed significantly. CSF leak repair has advanced from the conventional open intracranial approaches by neurosurgeons to the transnasal endoscopic ones by otorhinolaryngologists. In this study, 35 patients with CSF leaks underwent endoscopic repair with a $94.3 \%$ first attempt success rate, and $100 \%$ overall success rate. There were no major intraoperative or postoperative complications. To conclude, the endoscopic approach has a high success rate with minimal morbidity and has therefore, become the preferred method.
\end{abstract}

Keywords: Skull base, CSF rhinorrhea, Repair, Endoscopic.

How to cite this article: Jain A, Singhal P, Sharma MP, Singh SN, Grover M. Transnasal Endoscopic Cerebrospinal Fluid Rhinorrhea Repair: Our Experience of 35 Cases. Clin Rhinol An Int J 2014;7(2):47-51.

\section{Source of support: Nil}

Conflict of interest: None declared

\section{INTRODUCTION}

Cerebrospinal fluid (CSF) rhinorrhea results from an abnormal communication between subarachnoid space and nose due to breakdown of all the barriers between them, namely, arachnoid membrane, dura mater, bone of skull base and the mucosa of nasal cavity and paranasal sinuses. It can be traumatic or nontraumatic in origin. The incidence of CSF rhinorrhea has increased greatly as a result of the alarming rise of road traffic accidents and advanced endoscopic skull base surgeries. The commonest cause of CSF leaks is accidental trauma, followed by iatrogenic trauma and nontraumatic spontaneous leaks. Most of the cases respond to

\footnotetext{
${ }^{1}$ Resident, ${ }^{2}$ Associate Professor, ${ }^{3}$ Professor and Head

${ }^{4,5}$ Assistant Professor

1-5Department of Otolaryngology and Head and Neck Surgery Sawai Man Singh Medical College and Hospitals, Jaipur Rajasthan, India
}

Corresponding Author: Avani Jain, Resident, Flat No. C-8 Tower 1, New Moti Bagh, New Delhi-110023, India, Phone: +91-9660697348, e-mail: avanijain87@hotmail.com conservative management, that includes - bed rest with reverse-Trendelenberg position, medical treatment and placement of lumbar drain. Any persistent CSF leak must be surgically repaired to avoid imminent life-threatening complications, like meningitis, brain abscess and pneumocephalus.

Galen, in the 2nd century AD, first described the leakage of CSF after cranial trauma, but it was not considered a pathologic process until the 17 th century. ${ }^{1}$ In 1826 , Charles Miller gave the first comprehensive description of CSF leak in a child with hydrocephalus. ${ }^{2}$ In 1899, Sir St Clair Thomson, reported a series of spontaneous nasal CSF leaks and coined the term 'CSF rhinorrhea'. ${ }^{3}$ The history of surgical repair of CSF rhinorrhea began in 1926 when, Walter Dandy, an American surgeon reported the first successful intracranial repair using a bifrontal craniotomy. ${ }^{4}$ This procedure has a success rate of 60 to $80 \%$. After nearly two decades, Gosta Dohlman, a Swedish physician, performed the first extracranial approach for the repair of a CSF leak from the roof of the ethmoid using a naso-orbital incision. ${ }^{5}$ In 1952, Oskar Hirsch was the first to repair a CSF leak in the sphenoid sinus using the trans-septal approach. ${ }^{6}$ Wigand, in 1981, performed the first successful transnasal endoscopic approach to repair anterior cranial base CSF rhinorrhea. Once considered the province of neurosurgeons, CSF leak repair was primarily managed by open intracranial approach. Over the past few decades, as a result of advances in endoscopic tools and techniques, the surgical management has changed significantly, and now, CSF leaks are being approached extracranially by minimally invasive endoscopic techniques by otolaryngologists. These approaches are associated with minimal morbidity and mortality, and over $90 \%$ success rate..$^{8-11}$

The aim of this study was to evaluate the outcomes in patients who underwent endoscopic repair of CSF rhinorrhea and to share our experience.

\section{PATIENTS AND METHODS}

This was a prospective study carried out in the Department of Otolaryngology and Head and Neck Surgery, SMS Medical College and Hospital, Jaipur, a tertiary level referral hospital. From November 2009 to December 2012, 35 patients who presented with CSF rhinorrhea were included 
in the study. Detailed history was taken including history of rhinorrhea, history of trauma/previous surgery, recurrent meningitis. Diagnosis was ascertained by nasal fluid analysis for glucose, electrolytes, cytology and proteins. Diagnostic rigid nasal endoscopy was done in all the patients. All patients underwent CT cisternography using metrizamide dye to localize the site of defect. MRI cisternography (Fig. 1) was reserved for the cases where the site of leak could not be localized by CT.

Transnasal endoscopic repair of CSF leak was done in all the patients under hypotensive anesthesia, using $4 \mathrm{~mm}$ $0^{\circ}$ and $30^{\circ}$ rigid nasal endoscopes. The location of fistula was identified using the nasal endoscope and the margins of the defect were defined. Nasal or sinus mucosa surrounding the defect was removed for around $5 \mathrm{~mm}$ to expose the bone around the defect, thereby allowing attachment of the graft to the bone. Cephalocoeles, if present, were managed by removing the mucosa from the mass and reducing the mass through the bony defect, by direct manipulation or by bipolar cautery (Fig. 2). Depending on the site and size of defect, fistula closure was done by underlay-overlay technique or bath

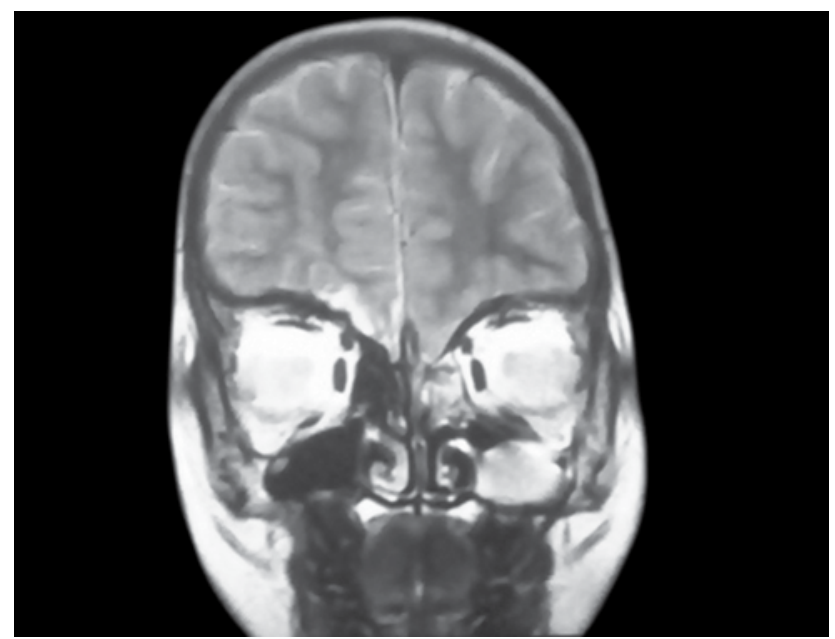

Fig. 1: MR cisternogram $5 \mathrm{~mm}$ defect seen in left cribriform plate with CSF leak through it and herniation of gyrus rectus also seen

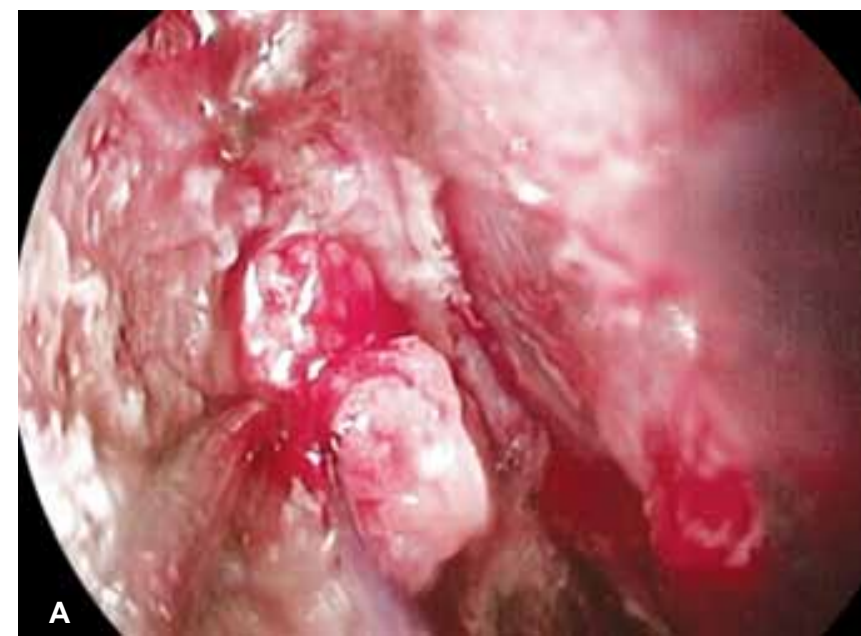

plug technique. Underlay-overlay technique was preferred for larger defects, in which repair was done in five layers. Adipose tissue and fascia lata were harvested from the thigh using a separate incision. The first layer was fat plugging the defect. Fascia lata was then tucked in by underlay technique between the dura and skull base. This was followed by a layer of microfibrillar collagen. The fourth layer was fascia lata placed by overlay technique, over the dural lesion and over the exposed bony margins, which were denuded of mucosa. Another layer of microfibrillar collagen was placed over this. Graft was stabilized using oxidized cellulose and absorbable gelatine sponge. Bathplug technique (Figs 3A and B) was used to seal small defects. In this method, adipose tissue was harvested from thigh/ear lobule. Fat was placed over the defect and incorporated intracranially. This was held in place by the ambient intracranial pressure as well as a soft tissue graft (fascia lata) centered over the defect with the edges of the centered graft exceeding the bony defect circumferentially. Next, a layer of microfibrillar collagen was placed over it. Graft was stabilized using oxidized cellulose and absorbable gelatine sponge.

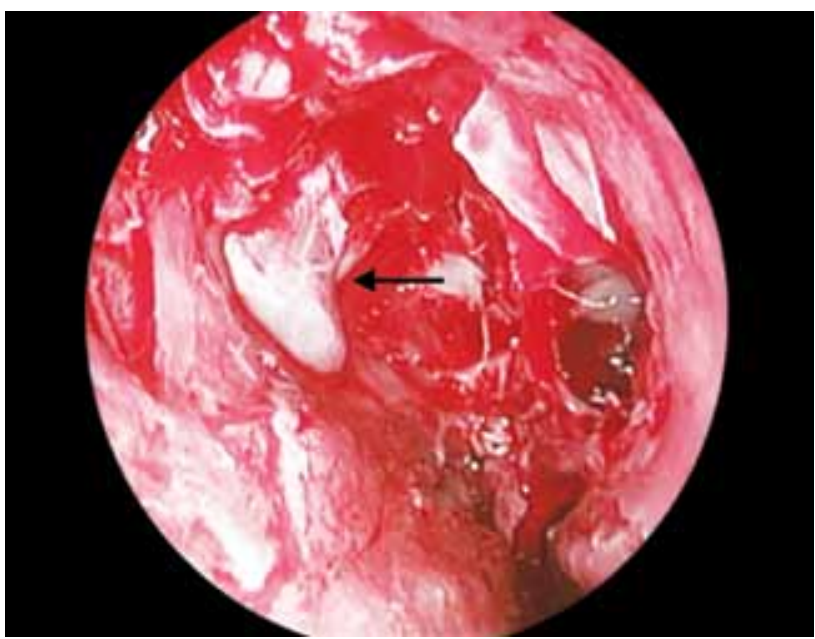

Fig. 2: Endoscopic image of a meningoencephalocele (arrow) from the cribriform plate (left side)

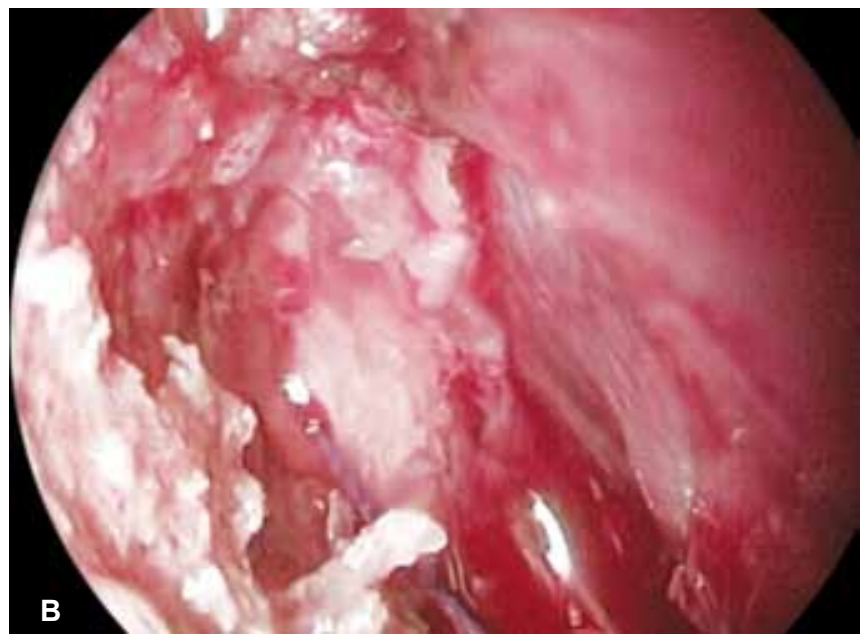

B

Figs 3A and B: Endoscopic image of fat being obliterated into the site of defect by bathplug technique 


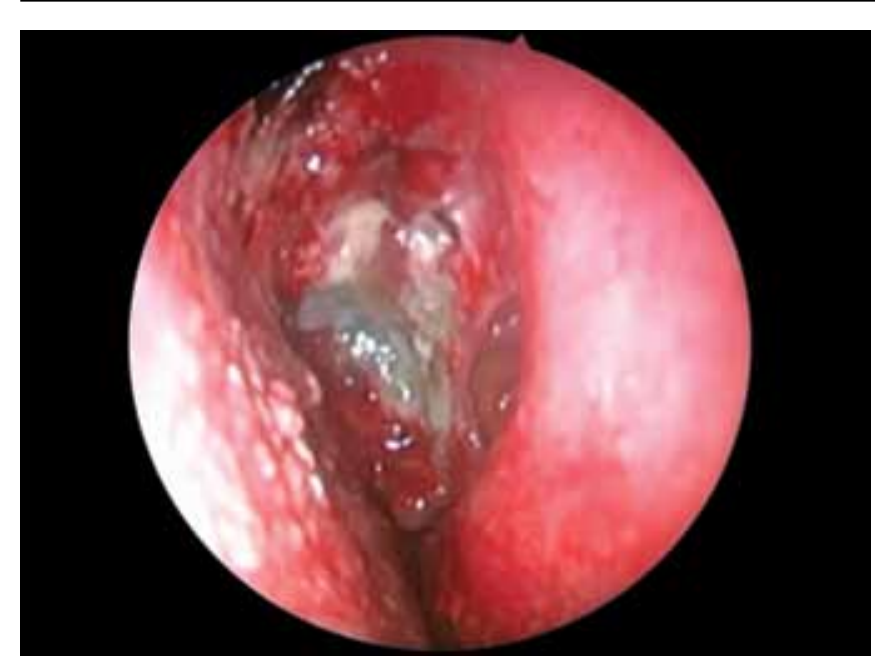

Fig. 4: Postoperative endoscopic image of a $8 \mathrm{~mm}$ defect in cribriform plate repaired by underlay-overlay technique

Following surgery, all patients were advised strict bed rest with head elevation $\left(30^{\circ}\right)$, minimal exertion and no straining. Postoperatively, all patients were given i.v. antibiotics - 3rd generation cephalosporin, aminoglycosides and anerobic coverage, i.v. mannitol, oral acetazolamide, cough suppressant and stool softeners. Nasal pack was removed 5 th to 7 th postoperative day. The patients were advised not to strain and lift heavy weights for at least 1 month and were prescribed cough suppressants and stool softeners. Follow-up was done by nasal endoscopy every fortnight for 2 months and then monthly to see for any recurrence (Fig. 4). The follow-up period varied from 6 to 24 months.

\section{RESULTS}

Among the 35 patients who were included in the study, there were 20 males and 15 females. Age group varied from 10 to 60 years with mean age of 35 years. CT cisternography indicated the site of leak in all but three cases in which MR cisternography was required. Five patients had coexistent cephalocoeles. Two patients had history of recurrent meningitis which was managed conservatively and following its resolution, these patients underwent endoscopic repair of CSF leak. None of the patients had bilateral leaks or prior attempted repair.

The most frequent site of cranionasal fistula was cribriform plate $(20 / 35 ; 57 \%)$, followed by roof of ethmoids $(10 / 35 ; 29 \%)$, sphenoid sinus $(4 / 35 ; 11 \%)$ and frontal sinus $(1 / 35 ; 3 \%)$.

From the etiological point of view, dural defects were classified into three groups:

Spontaneous/nontraumatic leaks $(20 / 35 ; 57 \%)$ - this group included patients with no history of trauma or previous surgery.
Surgical/iatrogenic trauma $(7 / 35 ; 20 \%)$ — these patients had history of previous nasal or skull base surgery: pituitary surgery in four patients, surgery for ethesioneuroblastoma in two patients and sinonasal procedure in one patient.

Accidental trauma $(8 / 35 ; 23 \%)$ - these patients had history of head injury due to road traffic accident or fall from height.

The closure technique depended on the location and size of the defect. The size of the defect varied from $2 \mathrm{~mm}$ to $1 \mathrm{~cm}$. We used the underlay-overlay technique in $28(80 \%)$ patients and the bathplug technique in $7(20 \%)$ patients (Table 1). None of the patients had any significant intra or postoperative complications. Three patients complained of postoperative headache which resolved within a few days.

CSF leak repair was successful at first attempt in 33/35 (94.3\%) patients, and an overall success rate, including revision of $100 \%$. Two patients presented with recurrence, out of which one had minimal leak which improved with only conservative management. The second patient underwent revision surgery and on follow-up the defect had completely resolved. The follow-up period varied from 6 to 24 months. The defect size and choice of surgical technique did not appear to influence the repair outcome.

\section{DISCUSSION}

Transnasal endoscopic repair of cerebrospinal fluid leaks is a major challenge for otorhinolaryngologists and skull base surgeons. The advances in technology have permitted its repair by the minimally invasive endoscopic technique. This approach is cost-effective, less time consuming, has minimal morbidity and mortality, and a very high success rate as compared to the open intracranial approach.

The etiology of CSF rhinorrhea can be traumatic or nontraumatic. The commonest cause of CSF rhinorrhea is traumaaccidental followed by iatrogenic. The anterior skull base is extremely prone to trauma both accidental and iatrogenic.

Table 1: Characteristics of cerebrospinal fluid leaks

\begin{tabular}{lll}
\hline & Number/total & Percentage \\
\hline Etiology & & \\
Spontaneous & $20 / 35$ & 57 \\
latrogenic trauma & $7 / 35$ & 20 \\
Accidental trauma & $8 / 35$ & 23 \\
Site & & \\
Cribriform plate & $20 / 35$ & 57 \\
Roof of ethmoids & $10 / 35$ & 29 \\
Sphenoid & $4 / 35$ & 11 \\
Frontal & $1 / 35$ & 3 \\
Surgical technique & & \\
Underlay-overlay & $28 / 35$ & 80 \\
Bathplug & $7 / 35$ & 20 \\
\hline
\end{tabular}


Table 2: Review of literature

\begin{tabular}{|c|c|c|c|c|c|}
\hline References & $\begin{array}{l}\text { No. of } \\
\text { patients }\end{array}$ & Etiology & Site of defect & $\begin{array}{l}\text { Graft material/surgical } \\
\text { technique }\end{array}$ & Results and follow-up \\
\hline $\begin{array}{l}\text { James A } \\
\text { Burns et al } \\
(1996)\end{array}$ & 42 & $\begin{array}{l}\text { Spontaneous }-10 \\
\text { Accidental trauma }-5 \\
\text { latrogenic trauma }-27\end{array}$ & $\begin{array}{l}\text { Sphenoid sinus }-20 \\
\text { Fovea ethmoidalis }-15 \\
\text { Cribriform plate }-7\end{array}$ & $\begin{array}{l}\text { Sphenoid fistulae-adipose } \\
\text { tissue with attached dermis or } \\
\text { fascia with fibrin glue } \\
\text { Fovea ethmoidalis and cribri- } \\
\text { form plate fistulae-middle turbi- } \\
\text { nate graft with fibrin glue }\end{array}$ & $\begin{array}{l}\text { Success rate }-90.4 \% \\
(38 / 42)\end{array}$ \\
\hline $\begin{array}{l}\text { R Hughes } \\
\text { et } \mathrm{al}^{15}(1997)\end{array}$ & 17 & $\begin{array}{l}\text { Spontaneous }-6 \\
\text { Accidental trauma }-2 \\
\text { latrogenic trauma }-9\end{array}$ & $\begin{array}{l}\text { Sphenoid sinus }-5 \\
\text { Fovea ethmoidalis }-6 \\
\text { Cribriform plate }-4 \\
\text { Lateral lamella-2 }\end{array}$ & $\begin{array}{l}\text { Free turbinate mucosa }-12 / 17 \\
(70.6 \%) \\
\text { Fascia lata and fat }-5 / 17 \\
(29.4 \%)\end{array}$ & $\begin{array}{l}\text { First attempt success } \\
\text { rate }-94.1 \%(16 / 17)\end{array}$ \\
\hline $\begin{array}{l}\text { JL Zweig } \\
\text { et al }{ }^{8}(2000)\end{array}$ & $\begin{array}{l}48 \\
\text { patients } \\
\text { with } 53 \\
\text { leaks }\end{array}$ & $\begin{array}{l}\text { Spontaneous }-12 \\
\text { Accidental trauma }-11 \\
\text { latrogenic trauma }-27 \\
\text { Hydrocephalus }-2 \\
\text { Neoplasm }-1\end{array}$ & $\begin{array}{l}\text { Sphenoid sinus }-19 \\
\text { Cribriform plate }-19 \\
\text { Fovea ethmoidalis }-15\end{array}$ & $\begin{array}{l}\text { Overlay technique }-24 / 53 \\
(46 \%) \\
\text { Underlay technique }-17 / 53 \\
(32 \%) \\
\text { Obliteration of sphenoid sinus } \\
\text { or sella }-12 / 53(22 \%)\end{array}$ & $\begin{array}{l}\text { First attempt success } \\
\text { rate-95\% (50/53) } \\
\text { Second } \\
\text { attempt-100\% }\end{array}$ \\
\hline $\begin{array}{l}\text { M Cassano } \\
\text { et al }{ }^{12}(2009)\end{array}$ & 125 & $\begin{array}{l}\text { Spontaneous }-43 \\
\text { Accidental trauma }-41 \\
\text { latrogenic trauma }-29 \\
\text { Skull base tumor }-12\end{array}$ & $\begin{array}{l}\text { Sphenoid sinus }-43 \\
\text { Cribriform plate }-42 \\
\text { Anterior ethmoid }-21 \\
\text { Posterior ethmoid-17 } \\
\text { Frontal sinus }-2\end{array}$ & $\begin{array}{l}\text { Overlay apposition of a lower } \\
\text { turbinate mucoperiosteal flap } \\
\text { fixated with fibrin glue and } \\
\text { surgical }\end{array}$ & $\begin{array}{l}\text { First attempt success } \\
\text { rate }-94.4 \%(118 / 125)\end{array}$ \\
\hline Present study & 35 & $\begin{array}{l}\text { Spontaneous }-20 \\
\text { Accidental trauma }-8 \\
\text { latrogenic trauma }-7\end{array}$ & $\begin{array}{l}\text { Cribriform plate }-20 \\
\text { Roof of ethmoids }-10 \\
\text { Sphenoid sinus }-4 \\
\text { Frontal sinus }-1\end{array}$ & $\begin{array}{l}\text { Underlay-overlay }-28 / 35 \\
(80 \%) \\
\text { Bathplug technique }-7 / 35 \\
(20 \%)\end{array}$ & $\begin{array}{l}\text { First attempt success } \\
\text { rate-94.3\% (33/35) } \\
\text { Second } \\
\text { attempt-100\% }\end{array}$ \\
\hline
\end{tabular}

The dura in this region is tightly adherent to underlying skull, and trauma can result in CSF rhinorrhea. Most of these leaks subside with conservative management and surgery is not required. Dural defects though rare, must be closed regardless of the cause due to potential risk of life threatening complications like meningitis and pneumocephalus.

In our study, a diverse age group of patients from 10 to 60 years underwent endoscopic repair of CSF leaks. Males were predominantly affected, with a male to female ratio of 1.3:1, in concordance with other studies. ${ }^{8,11,12}$ Diagnosis was by history of intermittent rhinorrhoea, nasal fluid cytological and biochemical analysis and rigid nasal endoscopy. Fluid analysis for $\beta 2$ transferrin or B trace protein is highly sensitive, however, these tests were not available in our clinical set up. CT scan was effective in localizing site of defect in most cases. MRI being more sensitive, was used for detection of site of leak when CT was inconclusive and in cases of meningoencephalocoele. Two of the patients had history of recurrent meningitis. None of the patients had pneumocephalus, bilateral leaks or prior attempted repair.

The commonest cause of CSF rhinorrhea in our study was spontaneous leaks, followed by accidental trauma and iatrogenic causes. This was in contrast to other studies, ${ }^{8,9,12}$ where trauma was the most common cause. Cribriform plate was the predominant site of leak, as found in literature. ${ }^{9,10}$ In our study, there were ten patients with defect in roof of ethmoids, four in sphenoid sinus and one with frontal sinus defect. We did not use intrathecal fluorescein to identify site of leak because of suspected neurological complications.

All patients underwent endoscopic repair of CSF leak with a 94.3\% success rate at first attempt and the overall success rate of CSF leak repair, including revision, was $100 \%$. This was in concordance with the results obtained in other studies ${ }^{8-15}$ (Table 2). The defect was repaired, depending on the size, by underlay-overlay technique or bathplug technique. The high success rate was attributed to the multi-layered repair using fascia lata, adipose tissue, microfibrillar collagen and oxidized cellulose. Various other graft materials have been used in other studies to repair the defect-nasal cartilage and mucoperichondrium, ${ }^{8-10}$ middle turbinate flap, ${ }^{8,9,11,13,14}$ fibrin glue. ${ }^{8,13,14}$ We did not use any of these in our study. Several authors recommend the use of postoperative lumbar drain. However, in our study, we did not find it necessary and lumbar drain was not used in any of the patients. The patients were followed up for 6 to 24 months. It was found that the size of the defect and choice of surgical technique did not affect the outcome.

\section{CONCLUSION}

Transnasal endoscopic repair of CSF rhinorrhea is a safe and effective method, with minimal morbidity and as such 
no mortality. A multilayered technique using fat, fascia, microfibrillar collagen and oxidized cellulose to repair the defect has a high success rate. Therefore, transnasal endoscopic technique has become the preferred method for repair of cranionasal fistula.

\section{REFERENCES}

1. Zlab MK, Moore GF, Daly DT, et al. Cerebrospinal fluid rhinorrhea: a review of the literature. Ear Nose Throat J 1992; 7:314-317.

2. Miller C. A case of hydrocephalus chronicus, with some unusual symptoms and appearance on dissection. Trans Med Chir Soc 1826;2:243-248.

3. Thomson St C. The cerebrospinal Fluid: its spontaneous escape from the nose. London: Cassell 1899.

4. Dandy WE. Pneumocephalus (intracranial pneumatocele or aerocele). Arch Surg 1926;12:949-982.

5. Dohlman G. Spontaneous cerebrospinal rhinorrhea. Acta Otolaryngol 1948;67(suppl):20-23.

6. Hirsch O. Successful closure of cerebrospinal fluid rhinorrhea by endonasal surgery. Arch Otolaryngol 1952;56:1-13.

7. Wigand ME. Transnasal ethmoidectomy under endoscopic control. Rhinology 1981;19:7-15.
8. Zweig JL, Carrau RL, Celin SE, et al. Endoscopic repair of cerebrospinal fluid leaks to the sinonasal tract: predictors of success. Otolaryngol Head Neck Surg 2000;23:195-201.

9. Lindstrom DR, Toohill RJ, Loehrl TA, Smith TL. Management of cerebrospinal fluid rhinorrhea: the Medical College of Wisconsin experience. Laryngoscope 2004;114:969-974.

10. Lanza DC, O'Brien DA, Kennedy DW. Endoscopic repair of cerebrospinal fluid fistulae and encephaloceles. Laryngoscope 1996;106:1119-1125.

11. Mirza S, Thaper A, McClelland L, Jones NS. Sinonasal cerebrospinal fluid leaks: management of 97 patients over 10 years. Laryngoscope 2005;115:1774-1777.

12. Cassano M, Felippu A. Endoscopic treatment of cerebrospinal fluid leaks with the use of lower turbinate grafts: a retrospective review of 125 cases. Rhinology 2009;47:362-368.

13. Burns J, Dodson E, Gross C. Transnasal endoscopic repair of cranionasal fistulae: a refined technique with long-term followup. Laryngoscope 1996;106:1080-1083.

14. Lee DH, Lim SC, Joo YE. Treatment outcomes of endoscopic repairs of sinonasal cerebrospinal fluid leaks. J Craniofac Surg 2011;22:1266-1270.

15. Hughes RG, Jones NS, Robertson IJ. The endoscopic treatment of cerebrospinal fluid rhinorrhea: the Nottingham experience. J Laryngol Otol 1997;111:125-128. 